\title{
Inclusive STEM Education: Theoretical Framework for Examining the Experienes of Women Students of Color in STEM Education
}

\author{
Kelly Kim
}

May 7th, 2019

\begin{abstract}
Women students of color (WSOC) continue to be excluded from science, technology, engineering and mathematics (STEM) fields, despite efforts to promote diversity. The existing research to develop inclusive STEM education adopts a deficit approach and fails to address the intersectionality of gender, race and class. By not addressing this intersectionality, research has failed to consider the effects of racial privilege for white women and the unique experiences of each woman of color. In contrast, my research will take an antideficit approach and value the intersectionality of each student. The objective of this study is to examine the experiences of WSOC in their secondary STEM education according to the intersection of race, gender and class. This research is also guided by the following questions: (1) What are WSOC's social and academic experiences of STEM-related courses, and in-class and extracurricular activities? (2) What support systems and barriers do WSOC recognize in their schools pertaining to STEM, if any? (3) How are their experience, support systems and barriers unique yet similar according to their intersectionality? This paper develops the theoretical approach that guides my research. To better understand how WSOC are racialized and gendered in the settler state, I adopt Critical Race Theory (CRT) approach. In the education setting, it describes how schools, as a state funded institute, act as a site of reinforcement of this oppression. I also incorporate poststructualist work on identity and power to refine how WSOC are situated in the STEM education setting. The research will adopt the Counter-Storytelling as a methodology which emphasizes the importance of telling the stories of people, whose experiences are not often told to expose, analyze and challenge the majoritarian stories of racial privilege.
\end{abstract}

\section{Introduction}

My experience as a woman student of color (WSOC) and a teacher of WSOC allowed me to develop a great interest and insight into the intersections of racism and sexism in the culture of science, technology, engineering and mathematics (STEM) education. When I came back to McGill University after nearly two years of teaching science and math to girls from marginalized communities, my purpose of reform in STEM education was fuelled by the racial and gender injustice that I experienced, witnessed and perpetuated. Studying critical race theory (CRT) has not only answered, clarified and validated the intersectional injustice encompassing race, gender and class that I couldn't understand beforehand but also provided me with theories, concepts and language to ground my research. Therefore, I will use CRT as the primary theoretical framework to understand how racism, sexism and classism, not as separate but as interlocking oppressive structures, are endemic to the history, laws, economy and values of the settler state. As I draw on the tenets of CRT, I will also incorporate post-structuralist work to define identity and to posit and challenge the power structures in STEM education that impacts the experiences of WSOC. Then, I will introduce counter-storytelling as the methodology for this research, which is derived from CRT and is a good fit for my research objectives and questions. I believe that this theoretical framework won't only substantiate the research in inclusive STEM education but it will also be a first step to amend the harm that previous research have done by excluding, problematizing and essentializing WSOC and their experiences. This theoretical framework helped to formualate my research objective which is to examine 
the experiences of WSOC in their secondary STEM education according to the intersection of race, gender and class. It also guided to ask the following research questions: (1) What are WSOC's social and academic experiences of STEM-related courses, and in-class and extracurricular activities? (2) What support systems and barriers do WSOC recognize in their schools pertaining to STEM, if any? (3) How are their experience, support systems and barriers unique yet similar according to their intersectionality?

\section{Critical Race Theory (+ Post-Structuralism)}

CRT shows that racism is endemic in the structure of the state and therefore its law and state-funded institutions (Matsuda, Lawrence, Delgado \& Crenshaw, 2018; Smith, 2012). CRT scholars challenge ahistoricism and make explicit connections to history to contextualize the current law which dictates contemporary issues of privilege and disadvantage of race groups, including education, imprisonment, health, political representation, and housing (Matsuda et al., 2018). Here, I expand on few of the tenets of CRT that is important to understand WSOC's intersectional identities where they are racialized, gendered and classed and how these oppressions are interlocked in the setting of STEM education. The tenets include: Settler-Colonialism, the critique ofliberalism and liberal education, whiteness as property, and intersectionality. Furthermore, I refine my approach to interesectionality by defining identity and examining the power structures in STEM education using post-structuralist work.

\subsection{Settler-Colonialism}

Settler colonialism is a critical theoretical framework that reveals how white supremacy has emerged a racialized and gendered national identity that normalized male whiteness in the settler state (Glenn, 2015). It is emphasized that settler colonialism is not a historical event but an ongoing structure where " $[\mathrm{t}]$ he logic, tenets, and identities engendered by settler colonialism persist and continue to shape race, gender, class, and sexual formations into the present"(Glenn, 2015, p. 55). I include settler colonialism as the first tenet to recognize "decolonization as a necessary goal in the quest to achieve race and gender justice" (Glenn, 2015, p. 52). Smith (2012) criticizes the traditional melting-pot approach to understanding racism which focuses on overlapping experiences of oppression between communities of color while neglecting critical differences between groups. This results in scholars focusing on the unaddressed uniqueness in the history of oppression of particular groups in their work on racial solidarity. Instead, Smith (2012) presented a conceptual tool, three pillars of white supremacy, "to rearticulate our understanding of white supremacy by not assuming that it is enacted in a singular fashion; rather, white supremacy is constituted by separate and distinct, but still interrelated logics" (Smith, 2012, p. 68). The first primary logic of white supremacy is slaveability/anti-Black racism, which anchors capitalism. In this logic, Black people are inherently slaveable, even after emancipation, they are consistently equated as a permanent property of the state. This logic anchors the capitalist system as it allows commodifying all of its workers while applying a racial hierarchy to this system where non-Black people feel complacent in their place in the system because they're not at the bottom of the hierarchy (Smith, 2012). The second pillar of white supremacy is genocide which anchors colonialism. This pillar represents the logic that the disappearance of indigenous peoples will grant the rightful claim to indigenous land, resources and culture to nonindigenous people. As stated before, it is important to note that the erasure of Indigenous people, culture, language and history is an ongoing project to achieve the goal of acquiring Indigenous peoples' properties. The last pillar is the logic of orientalism which anchors war. Orientalism was introduced by Said (1994), where the Orient is viewed as inferior, exotic, uncivilized while the west defines itself as the superior civilization. Although the Orient is not considered as property or subject to erasure, they are positioned as a permanent foreign threat to the West, even when they have resided in the settler state for a long time as an immigrant. Therefore, orientalism anchors the logic of war, where the settler state "justi[fies] being in a constant state of war to protect itself from its enemies." (Smith, 2012, p. 70).

The three pillars of white supremacy is a critical concept to centralize in the discussion of racial solidarity of WSOC as it focuses on white supremacy as the driving force that uniquely racializes WSOC rather than individualizing everyone's history and nature of oppression. Glenn (2015) argues that settler-colonialism is not only 
a project of racialization but also genderization to construct a hierarchy of humankind. As settlers rendered the indigenous peoples as expandable and invisible, settlers conceived themselves as "more advanced and evolved, bringers of progress and enlightenment to the wilderness" (Glenn, 2015, p. 58). Thus masculine whiteness became fundamental to settler identity which is closely associated with ownership of property and political sovereignty (Glenn, 2015). This heteropatriarchy not only feminizes (e.g. take away the masculine rights of property ownership and political freedom and power) white women and women of color but also masculinizes the white race in relation to feminized Black, indigenous and orient races (Glenn, 2015; Razack, 2005). As settler-colonialism clearly reveals how racialization and genderization interlocks it guides this research to identify how white supremacy in the form of racism, sexism, classism and other systems of oppression shape the experiences of WSOC in the context of STEM education.

\subsection{The critique of liberalism and liberal education}

Liberalism focuses on individual rights and prevents any special protection for minority groups, as it might lead to unequal power dynamics. "Ultimately, the liberal perspective fails to consider the multiple power relationships that give some individuals much greater advantage over others, and that allow some people to be freer than others" (Zamudio, Russell, Rios \& Bridgeman, 2010, p. 16). The laws which order our society have once allowed genocide and slavery, denied fundamental human rights for Black and Indigenous people and gave second-class status to women(Zamudio et al., 2010). Although the laws have eventually progressed to extend legal and political rights to these people, these racist values and practices fundamentally remain, and the materialistic gains that the dominant group has accrued through the capitalist development continue to serve the discrepancy in power (Zamudio et al., 2010). CRT asserts that educational institutions reproduce racial injustices where minority children experience poorer schools both in funds and resources, incompetent teaching, and lower grades which ill-prepares students for the economic market (Dumas \& ross, 2016; Gillborn, 2008; Zamudio et al., 2010). Liberal educational reforms addressing racial inequalities in attainment take a deficit approach, and focuses on opening access to schools but not address the quality of education (Zamudio et al., 2010). CRT scholars argue that given the historical and institutional nature of race and racism, it is inevitable that the liberal educational policies and practices that attempt to narrow the gap between whites and students of color have failed as they can't alter the experiences of students of color without challenging the larger systems in society (Zamudio et al., 2010). Similarly, I challenge the liberal STEM education and policies to promote diversity in STEM education as it does not fully address the power structures within STEM discipline and the oppressive STEM culture and simply take a deficit model to integrate WSOC, where they struggle to persist due to the climate in STEM fields (Ong, Smith \& Ko, 2017; Ong, Wright, Espinosa \& Orfield, 2011).

\subsubsection{Meritocracy}

The notion of a meritocratic society assumes a "level playing field where all individuals in society have an equal opportunity to succeed" (Zamudio et al., 2010, p. 12). Specifically, it assumes that one's work ethic, values, intelligence and aptitude will determine an individual's success or failure. In the educational context, meritocracy allows institutions and policymakers to explain students' failure as a result of lack of effort, motivation or abilities rather than the structurally unequal society that inhibits their achievement (Zamudio et al., 2010). CRT scholars not only contest the idea of meritocracy as it fails to offer equal opportunities but also because it enacts as racial inequality (Zamudio et al., 2010). This type of individualistic approach also reduces racial injustice to a "series of randomly occurring, intentional and individualized acts" (Matsuda et al., 2018, p. 6), and avoids recognizing racism as a structure embedded into our society's laws and values. Meritocracy places the responsibility of students' success in STEM disciplines to the student, teachers, and parents instead of recognizing and criticizing the sociopolitical aspect of STEM discipline which actively excludes and contingently include (Glover \& Palgrave, 2000) WSOC and their knowledge. 


\subsubsection{Interest Convergence}

Interest convergence (Bell, 1980) is a concept that illustrates how progress in racial reforms happens cyclically rather than linearly. In other words, it answers the question, why is it so difficult and slow to bring about change? This tenet also shows how the progression from de jure discrimination such as genocide, slavery and war becomes an obstacle to destruct white supremacy embedded in the state's law and institutes. Bell (1980) introduced the principle of interest convergence as "[t]he interest of blacks in achieving racial equality will be accommodated only when it converges with the interests of whites" (Bell, 1980, p. 523). For example, while multicultural education is promoted as an attempt to include ethnic minorities, in fact, it is "the fallout of a political project to deluge and neutralize Black rejection of the conformist and assimilationist curriculum models solidly in place in the 1960s" (Grant \& Chapman, 2008, p. 188). Therefore, it is also an attempt to assure the safety of whites while minimizing changes in education (Zamudio et al., 2010). Interest convergence is also evident in the efforts to recruit and retain women, people of color and women of color in STEM education. Studies that are meant to address the underrepresentation of women of color in STEM argue that diversity in STEM disciplines is required to benefit the scientific community which contribute to national security, economy and quality of life (Gay-Antaki \& Liverman, 2018; Ong, Wright, Espinosa \& Orfield, 2011; Osei-Kofi \& Torres, 2015). Efforts to serve equity in STEM must take an approach to destruct the systems of oppression in place rather than integrating minority groups and placing them in a toxic culture for the interests of the whites. If attempts for diversity in STEM fail to do so, it is perpetuating white supremacist values.

\subsection{Whiteness as Property}

It is crucial to differentiate whiteness and white people: "“whiteness' is a racial discourse, whereas the category 'white people' represents a socially constructed identity, usually based on skin color" (Leonardo, 2002, p. 31). Whiteness is constructed as "property" and withheld from people of color (Smith, 2012). Leonardo (2002) stated that the defining characteristics of whiteness include denying inequity that is caused by white people, 'othering' of racial experience and groups, and minimizing the racist legacy by negating the essential historical, economic and cultural factors (Leonardo, 2002). In the educational context, research often In the educational context, research often identifies "whiteness as property" in educational policies and practices that maintain the achievement gap through school disciplines, testing, and access to culturally relevant curricula (Dumas \& ross, 2016). In the following section, proximity to whiteness, we can see how whiteness is contingently allowed to people of color who are willing to co-opt and therefore give contingent placement in STEM industries.

\subsubsection{Proximity to whiteness}

Whiteness is also seen as a default cultural standard (Zamudio et al., 2010). On the Black-white binary, being sufficiently distant from Blackness and close to whiteness can disqualify one from being racialized; therefore, proximity to whiteness allows racialized groups to some racial privilege and disappear into white society (Smith, 2012). Non-Black people accept their own racialization because they can feel that "at least they are not at the very bottom of the racial hierarchy: at least they are not property; at least they are not slaveable" (Smith, 2012, p. 69). This concept hinders solidarity of people of color to combat white supremacy, as some people of color stay close to whiteness and benefits from whiteness, they remain complicit and even protective of questioning the source of their privilege. This is also observed in women in science with masculinity as they internalize heteropatriarchy and disassociate themselves from femininity by referring themselves as "non-participants of traditional femininity" (Danielsson, 2012). Although these women in science experience isolation in the predominantly male environment, as contingent participants of STEM culture, they fail to challenge masculinity while distancing themselves from femininity. This allows them to get closer to masculinity and therefore whiteness (Danielsson, 2012). This proximity to whiteness is important to note with WSOC in STEM, because often one must conform to the rules of the game to succeed. In the discussion of coalition we must recognize the inevitable incommensurablility WSOC face when they search for equity within the laws, economy, and institutions of the settler state(Amadahy \& Lawrence, 2009). 


\subsection{Intersectionality}

Crenshaw (1990) introduced the concept of intersectionality to criticize and address the continuous marginalization of Black women in the feminist and antiracist discourses that took a "single-axis framework" and failed to consider intersectional identities of Black women (Crenshaw, 1990; Zamudio et al., 2010). She argued that Black women are excluded "within the traditional boundaries of race or gender discrimination as these boundaries are currently understood, and that the intersection of racism and sexism factors into Black women's lives in ways that cannot be captured wholly by looking at race or gender dimensions of those experiences separately" (Crenshaw, 1990, p. 1224). Crenshaw (1990) acknowledged that intersectionality should consider other factors such as class, sexuality, and age as they are critical in shaping the lived experiences of Black women; however, she focused on the intersections of race and gender to emphasize "the need to account for multiple grounds of identity when considering how the social world is constructed" (p.1245).

Since Crenshaw's work on intersectionality, CRT feminist scholars in Latinx and Indigenous communities adopted the idea of intersectionality to move beyond the single axis understandings of oppression and consider the intersectionality of privilege and disadvantage of women of color (Zamudio). As the concept of intersectionality became prominent in the anti-oppressive discourse, criticism of intersectionality and different approaches to intersectionality arose. Erevelles and Minear (2010) criticized the "unconscious non-analysis of disability as it intersects with race, class, and gender oppression" (p. 128) in the work of critical race feminists. However, they also problematized the additive approach to intersectionality as this approach raises questions such as: "[is it] even conceivable to address all these possible social categories intersecting with a common master category (e.g.race or gender) at any given time? Do some differences acquire greater prominence than others (e.g. sexuality)? Are some "other" differences just added on to merely complicate and "nuance" this intersectional analysis (e.g. disability)? (Erevelles and minear 130-131). The authors suggested an intercategorical approach which is an approach "to analyse the differential ways by which social divisions are concretely enmeshed and constructed by each other and how they relate to political and subjective constructions of identities" (Yuval-Davis, 2006, p. 205). I will adopt this intercategorical approach to focus on how the systems of oppression affect WSOC's differently while avoiding to individualize and prioritize each of their experience.

\subsubsection{Intersectionality of WSOC in STEM Education}

Although this research focuses on the intersectionality of race, gender and class to emphasize and address the lack of intersectionality in the studies of inclusive STEM education, in its process and analysis, I will be mindful of the complex nature of intersectionality. Instead of attempting to address all the possible social categories such as race, cis- and trans-gender, class, disability, nationality, sexuality, religion, and more, the focus will lie on the participating WSOC's intersectional identity, how each is unique in their position (e.g. racialized uniquely), and how they are implicated and affected by similar social structures (e.g. white supremacy).

As CRT scholars have already done, I will also refine my intersectionality analysis by incorporating a poststructuralist way of defining identity as performativity (Butler, 2002). Theory of identity performance defines identity not only as what one identifies themselves as but as how one performs their identity through discourse and how others interpret and influence this identity (Butler, 2002; Gutierrez, 2013; Zamudio et al., 2010). Furthermore, I emphasize the position of WSOC as a student to acknowledge the additional power structure they are under as a student taking on mandatory education rather than women of color who are partaking a more independent education or career path. Generally, in an educational institute, students' are under surveillance and therefore shaped by school administrators, teachers, parents, peers, curriculum and standardized exams. However, there are also subtle power structures as Gutiérrez (2013) illustrated, which are evident in the context of math education. She suggested that there are two significant constructs in power in math education: the power of mathematics and the power associated with being successful in mathematics. The power of mathematics is implied in arguments such as "mathematics, as a rational, universal, and logical discipline is located in a unique position to be the ultimate arbiter of truth. Its ability to model the real world and to maintain a kind of internal certainty gives evidence of this privileged and earned position. Something proven with mathematics is seen to have final say" (Gutierrez, 2013, p. 47). This concept is foundational to assertions that learning math will give students power in society. The power associated with those who are successful in math follows that 
succeeding in this discipline follows with higher self-esteem, intelligence and even "insider" status (Gutierrez). This research will attend to how WSOC's identity and how these obvious and subtle power structures shape their experience in STEM education.

\section{Counter-Storytelling}

This research adopts the counter-storytelling methodology which is a critical race methodology that examines the stories of people whose experiences are often not told to expose, analyze and challenge the majoritarian stories of racial privilege (Solórzano \& Yosso, 2002). Critical race methodology in the education context has the following aims: (1) to center race and racism in the research process; (2) to challenge the traditional research paradigms that disguises as an objective stance while taking a deficit approach towards the experiences of students of color; (3) to addresses the intersectionality while challenging the separate discourse on race, class and gender to offer a liberatory or transformative solution; (4) to centralize the racialized, gendered, and classed experiences of students of color; (5) to use interdisciplinary knowledge including ethnic studies, feminism, poststructuralism, history and law to better comprehend and situate the experiences of students of color (Solórzano \& Yosso, 2002). These objectives collectively confront the existing majoritarian narrative that silence and distort the epistemologies of students of color. This majoritarian story also essentializes the experiences students of color by using a "standard formulae" to disguise as a neutral and objective narrative while implying negative stereotypes about people of color. Moreover, critical race methodology aims to point racial injustice and injuries and identify its origins. "In examining the origins, critical race methodology finds that racism is often well disguised in the rhetoric shared "normative" values and "neutral" social scientific and educational principles and practices" (Solórzano \& Yosso, 2002, p. 27). The counter-storytelling methodology allows the victims of racism to find their voice by examining and validating their racist injuries (Solórzano \& Yosso, 2002). Ultimately, it has the aim to empower participants by telling their own stories and hearing others' stories to discover that they are not alone in their intersectional oppression. Participants learn how the rhetoric against them is constructed and learn how to defend themselves to this discourse.

\subsection{Three Types of Counter-Storytelling}

There are three different types of counter-narratives and stories: personal stories or narratives; other people's stories or narratives; composite stories or narratives (Solórzano \& Yosso, 2002). Personal stories or narratives is telling of an individual's experiences with racism, sexism, classism. It is often an autobiographical reflection of the author with their critical race analysis. Other people's stories or narratives are a narrative that presents someone else's story in a third-person voice to reveal experiences with intersectional oppressions. Lastly, the composite stories or narratives draw on various forms of "data" to recount the experiences of people of color with racism, sexism and classism. These stories can be used as "theoretical, methodological, and pedagogical tools to challenge racism, sexism, and classism and work toward social justice" (Solórzano \& Yosso, 2002, p. 23). For this research, I will use the combination of personal stories and other people's stories. The research involves WSOC including myself to tell our own stories, but their stories will be presented by me as a third person.

\subsection{Theoretical Sensitivity}

As a researcher, one must be attentive to the concept "theoretical sensitivity" which is introduced by Strauss and Corbin (1990). Theoretical sensitivity is the researcher's "attribute of having insight, the ability to give meaning to data, the capacity to understand, and capability to separate the pertinent from that which isn't" (Strauss \& Corbin, 1990, p. 42). In this study, my theoretical sensitivity is influenced by my own experiences as a WSOC in STEM and a science and math teacher of WSOC. The theoretical framework of the research is also grounded in CRT and is shaped by the supervision of Dr. Philip Howard who shares his expertise on CRT. Furthermore, the WSOC who are participating in this research will be invited into a focus group where they can build a community of validation and support towards their marginalization, challenge the dominant narrative 
by understanding and transforming established norms and teach others to combine their stories and reality to "construct another world that is richer than either the story or the reality alone" (Solórzano \& Yosso, 2002, p. 36).

\section{Discussion}

Although I believe this theoretical framework is best suited to guide research that discuss oppression against race and gender, it does have limitations. First of all, settler-colonialism is specific to the settler state and not directly applicable to countries such as the UK where there is an underrepresetation of WSOC in STEM as well. Secondly, although I take an intercategorical approach to intersectionality, it is important to note that I won't be able to closely examine intersectionality of sexuality, transgender, and disability due to the scope of my research. There are also other theories that could be suitable such as critical feminist theories or poststructuralist work. However, CRT encompasses these theories and makes explicit connections between systems of oppression including but not limited to racialization and gendering. Furthermore, I am incorporating poststructuralist work to emphasize the interrelation between these theoretical framework.

\section{Conclusion}

The theoretical framework of my research is centred in CRT with the incorporation of post-structuralism to attempt to comprehend the complex reality of the interlocking, non-linear and interchanging oppressive structures that shape WSOC's experience in their daily lives and STEM disciplines. Additionally, this framework posits the oppressive structures in the state and its institutions to challenge and counter the prominent deficit approaches taken in the equity and diversity programs in STEM education and industries. The counter-storytelling methodology allows transitioning my theoretical aims into praxis, as it centers the voices of WSOC to describe their lived experiences, identify the barriers and support system on their accord, and ultimately exposes the "deficit-informed research that silences and distorts epistemologies of [WSOC]" (Solórzano \& Yosso, 2002, p. 23). I acknowledge that my own experience, as a WSOC in STEM and a STEM teacher of WSOC, informs my interpretation and analysis of the theoretical framework and WSOC's stories. Although traditional research paradigm may view my positionality as a negative influence on the objectivity of the research, I adhere to CRT and counter-storytelling methodology to present my work as a valuable addition to the partial perspectives (Haraway, 1988) and a collaborative counter-story to challenge the oppressive culture of STEM and argue that reform is needed in the structures of STEM for the representation and contribution of WSOC to be valued. 


\section{References}

Amadahy, Z. \& Lawrence, B. (2009). Indigenous peoples and black people in canada: Settlers or allies? In Breaching the colonial contract (pp. 105-136). Springer.

Bell, D. A. (1980). Brown v. board of education and the interest-convergence dilemma. Harvard Law Review, $518-533$.

Butler, J. (2002). Gender trouble. routledge.

Crenshaw, K. (1990). Mapping the margins: Intersectionality, identity politics, and violence against women of color. Stan. L. Rev. 43, 1241.

Danielsson, A. T. (2012). Exploring woman university physics students 'doing gender'and 'doing physics'. Gender and Education, 24(1), 25-39.

Dumas, M. J. \& ross, K. M. (2016). "be real black for me" imagining blackcrit in education. Urban Education, $51(4), 415-442$.

Gay-Antaki, M. \& Liverman, D. (2018). Climate for women in climate science: Women scientists and the intergovernmental panel on climate change. Proceedings of the National Academy of Sciences, 115(9), 2060-2065. doi:10.1073/pnas.1710271115

Gillborn, D. (2008). Racism and education: Coincidence or conspiracy? Routledge.

Glenn, E. N. (2015). Settler colonialism as structure: A framework for comparative studies of us race and gender formation. Sociology of Race and Ethnicity, 1(1), 52-72.

Glover, J. \& Palgrave, C. (2000). Exclusions: American women of science. In Women and scientific employment (pp. 139-166). London, New York: Macmillan; St. Martin's Press.

Grant, C. A. \& Chapman, T. K. (2008). History of multicultural education: Foundations and stratifications. Routledge.

Gutierrez, R. (2013). The sociopolitical turn in mathematics education. Journal for Research in Mathematics Education, 44(1), 37-68.

Haraway, D. (1988). Situated knowledges: The science question in feminism and the privilege of partial perspective. Feminist studies, 14(3), 575-599.

Leonardo, Z. (2002). The souls of white folk: Critical pedagogy, whiteness studies, and globalization discourse. Race ethnicity and education, 5(1), 29-50.

Matsuda, M. J., Lawrence, C. R., Delgado, R. \& Crenshaw, K. (2018). Words that wound: Critical race theory, assaultive speech, and the first amendment. Routledge.

Ong, M., Smith, J. M. \& Ko, L. T. (2017). Counterspaces for women of color in stem higher education: Marginal and central spaces for persistence and success. Journal of Research in Science Teaching, 55(2), 206-245.

Ong, M., Wright, C., Espinosa, L. L. \& Orfield, G. (2011). Inside the double bind: A synthesis of empirical research on undergraduate and graduate women of color in science, technology, engineering,and mathematics. Harvard Educational Review, 81(2), 172-209.

Ong, M., Wright, C., Espinosa, L. \& Orfield, G. (2011). Inside the double bind: A synthesis of empirical research on undergraduate and graduate women of color in science, technology, engineering, and mathematics. Harvard Educational Review, 81(2), 172-209.

Osei-Kofi, N. \& Torres, L. E. (2015). College admissions viewbooks and the grammar of gender, race, and stem. Cultural Studies of Science Education, 10(2), 527-544. doi:10.1007/s11422-014-9656-2

Razack, S. H. (2005). How is white supremacy embodied-sexualized racial violence at abu ghraib. Can. J. Women \& L. 17, 341 .

Smith, A. (2012). Indigeneity, settler colonialism, white supremacy. In Racial formation in the twenty-first century. University of California Press. doi:10.1525/california/9780520273436.003.0005

Solórzano, D. G. \& Yosso, T. J. (2002). Critical race methodology: Counter-storytelling as an analytical framework for education research. Qualitative inquiry, 8(1), 23-44.

Yuval-Davis, N. (2006). Intersectionality and feminist politics. European journal of women's studies, 13(3), 193-209.

Zamudio, M., Russell, C., Rios, F. \& Bridgeman, J. (2010). Critical race theory concepts and education. In Critical race theory matters: Education and ideology. Taylor \& Francis. 